\title{
The Role of Information and Communication Technologies for Agricultural Development in Developing Countries
}

\author{
Abebaw Abebe \\ Raya University, Department of Agricultural Economics
}

\begin{abstract}
Major challenges to agricultural development in developing countries have been the low level of agricultural information exchange among the different stakeholders in the agricultural sector. Fortunately, the recently radical penetration of information and communication technologies (ICTs) tools in developing countries offers a great opportunity for overcoming information problems. Use information and communication technology (ICT) enables to facilitate rapid, efficient and cost effective knowledge management. The experiences of most countries indicate that the use of ICT based extension, marketing and banking which facilitates the flow of data and information, that has tremendously enhanced the knowledge management, financial inclusion and market efficiency. This paper has intended to review, the subscription and broadband level of ICTs in least developing countries and to review the role of ICTs for rural and agricultural development in least developing countries. To review this paper all recently(conducted before 2010) ICT for agriculture (ICT 4Ag) related journals, reports, conferences, working papers and other documents studied for developing countries had used.
\end{abstract}

Keywords: Agriculture; Developing countries; ICTs; Role

DOI: $10.7176 / J E S D / 11-15-04$

Publication date:August $31^{\text {st }} 2020$

\section{Introduction}

World population is expected to exceed 9 billion by 2050 and agriculture has to increase by at least $60 \%$ to feed this radical growth of population and ensure food security for all. Most of the increase in food production will have to take place in developing countries. However, millions of smallholder farmers are tackled by weak information flows (Okyere and Mekonnen, 2012; FAO, 2018). Major challenges to agricultural development in developing countries have been the low level of agricultural information exchange among the different stakeholders in the agricultural sector (Chukwunonso, 2012). Fortunately, the recently radical penetration of information and communication technologies (ICTs) tools in developing countries offers a great opportunity for overcoming information problems (Aker, 2010; Hopestone, 2014; Abebaw and Yared, 2018). Most of development partners of the world in all sector has been recognized the importance of ICTs. For instance, the 2030 Agenda for Sustainable Development recognizes that "The spread of information and communications technology and global interconnectedness has great potential to accelerate human progress, to bridge the digital divide and to develop knowledge societies" (UN, 2015).

ICT based, decision-making agricultural system (Precision Agriculture) is designed to production and is often described as the next great evolution in agriculture(Tigistu, 2014). ICTs can be used for information based decision in almost every step of agricultural production that include among others in input procurement, climate information, finance, production, distribution and marketing of agricultural produce (Bayissa, 2014). It influenced farmers decisions on what to plant, when to plant it, how to cultivate and harvest and where to store and sell and at what price (Okello, 2013).

Nearly 40 percent of the global population has access to the internet service (World Bank Group, 2016), and among the bottom fifth of the poor, more than four out of five people in the LDCs have access to a mobile-cellular network (ITU, 2018).The large adoption and integration of ICTs has reduced information and transaction costs, improved service delivery, created new jobs, generated new revenue streams and saved resources (FAO, 2018). The drastic subscription of ICTs particularly mobile phone in developing countries of poor farmers enable to reduce the transaction costs which accounts about more than $10-20 \%$ of the wholesale price. This cost is due to high logistic and transport costs (Word Bank, 2011) poor infrastructure, promotes market access(Okello et al., 2012), facilitates financial inclusion and risk management, contributes significantly to early warning, and can be central in revolutionizing agricultural extension(Samson, 2012).

Electronic-agriculture (e-agriculture) describes an emerging field focused on the enhancement of agricultural and rural development through improved information and communication processes (Abdulrahman et al., 2017). The ICT devices that help facilitating farming activities encompassed applications like radio, television, cellular phones, computers, tablets and networking, hardware and software, satellite systems (Munyua and Adera, 2009; Pande and Deshmukh, 2015).

Objective of the paper

This paper has intended to review and assess; 
\# The subscription and broadband level of ICTs in least developing countries,

\# The role of ICTs for rural and agricultural development in least developing countries.

\section{Methodology}

The data for this paper were reviewed mainly from issue of ICT for agriculture(ICT 4Ag) related journals, reports, conferences, working papers, reviews and case studies that were conducted in developing countries. Firstly, all ICT for agriculture (ICT 4Ag) related journals, reports, conferences, working papers and other documents studied for developing countries had retrieved. Secondly, most recently journals and documents from 2010 up to current were selected for this review.

\section{Discussion}

\section{ICT Coverage in Developing Countries}

Developing countries, and in particular the least developing countries(LDCs), lag behind developed countries in terms of fixed-broadband penetration, household access to ICTs and Internet uptake. Globally, 3.9 billion people, more than half the world's total population, are still offline and the majority of these people are from the world's most vulnerable countries, the LDCs, LLDCs and SIDS. Almost a fifth of the offline population over 800 million people - live in the LDCs.

Internet use (\% of population), LDCs

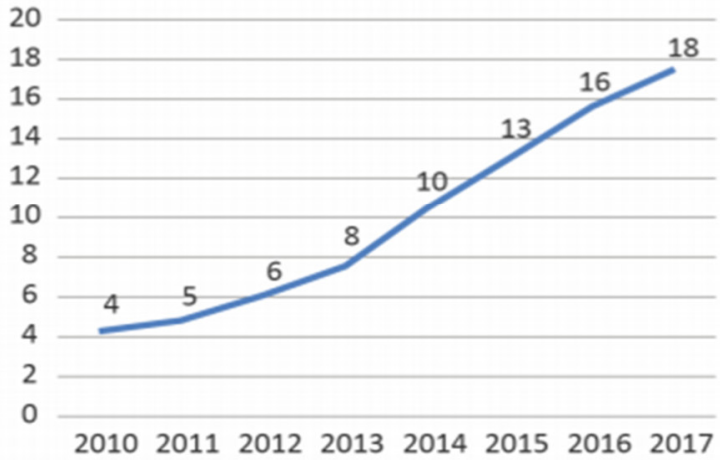

Distribution of population not online in LDCs, 2016

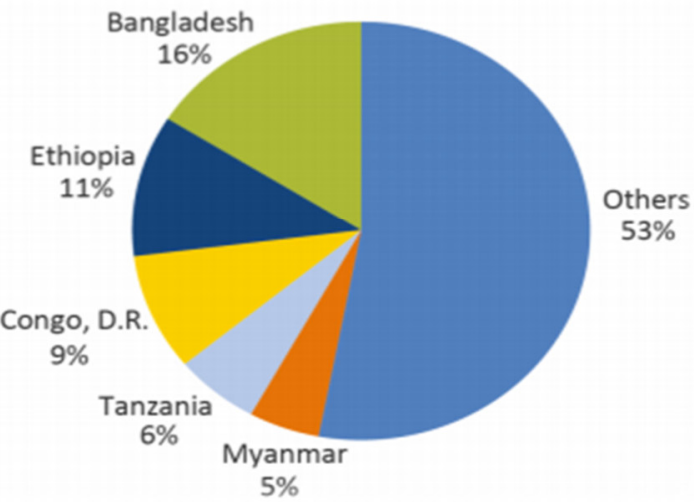

Figure 1. Broadband Internet for the LDCs

In contrast to relatively high mobile subscription penetration, Internet access remains low in the LDCs. It is estimated that by the end of 2017, only 172 million of the nearly 1 billion people living in the LDCs will be using the Internet, corresponding to a usage rate of about 17.5 per cent (Figure 1). It is estimated that over 800 million people in the LDCs are not online, and the five most populated countries (Bangladesh, Ethiopia, DRC, Tanzania and Myanmar) account for almost half that number (Figure 1) (ITU, 2017).

Developing countries, and in particular the LDCs, lag behind developed countries in terms of fixedbroadband penetration, household access to ICTs and Internet uptake. Globally, 3.9 billion people, more than half the world's total population, are still offline and the majority of these people are from the world's most vulnerable countries, the LDCs, LLDCs and SIDS. Almost a fifth of the offline population - over 800 million people - live in the LDCs (ITU, 2018). As indicated in figure 2.

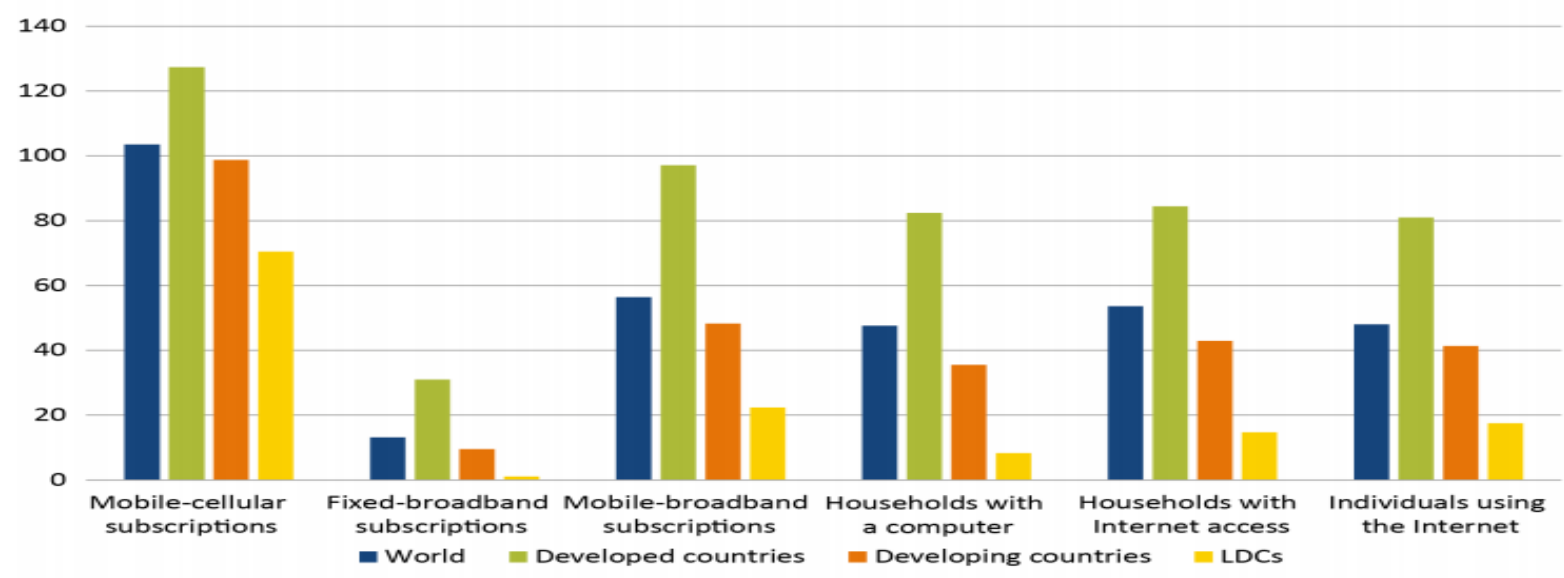

Figure 2.ICT subscription rate between developing and developing countries 


\section{Role of ICTs for Rural and Agricultural Development in LDCs}

ICT provides information related to weather/climate information, fertilizers consumption, online land registration, pest management and price output in the markets etc. Every level of agricultural development partners (researcher, universities, office of agriculture and extension workers) are connected with a network easily, to provide information to the farmers (Neelesh, 2017). ICTs can play a great role in rational decision making from the very beginning of agricultural production season to end of postharvest and marketing activates. as shown in figure 3 .

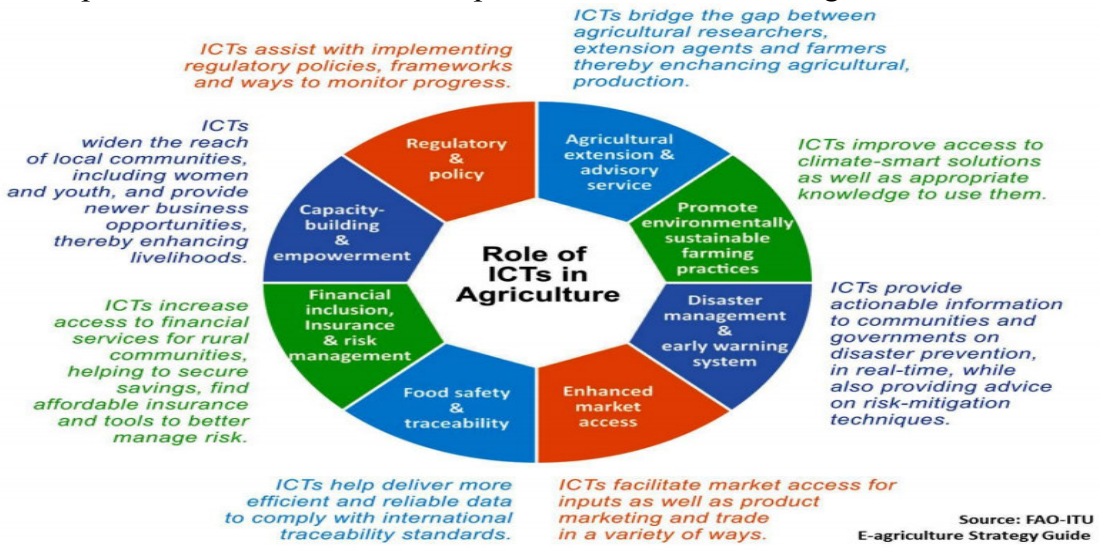

Figure 3 role of ICTs in agriculture at different season of agriculture

\section{ICT for Agricultural Extension (e-extension system)}

Most of the farmers in developing countries are geographically displaced and remote settlings. This makes agricultural extension system costly and very difficult to run personnel public extension system. Therefore, the fate of future extension system will be ICT based extension system. Knowledge sharing and training methods based on ICTs are important vehicles to improve access to information and enhance knowledge on sustainable production intensification technologies (FAO, 2018). ICTs can facilitate dialogue between stakeholders and across levels, and trigger learning with knowledge networks and platforms that provide a venue where the diverse actors can connect (FAO, 2013; Neelesh, 2017).Different countries have used different ICT application and service for e- extension (Yonazi, 2012). For instance, Esoko in Ghana, Kenya, India, Uganda and for other LDCs, NAFIS, Mfarm, KilimoSalama in Kenya, 8028 hotline in Ethiopia, ICT4Dev.ci in Ivory Cost, Digital Green in most of Sub-Saharan countries (Aker, 2010; Nakasone et al.,2014).

\section{ICT for agricultural marketing (e-marketing)}

In developing countries there are high logistic and transport costs (Word Bank, 2011), poor road infrastructure (Okello et al., 2012 which cases to market inefficiency. ICTs can bring significant benefits through better information on markets. Prices signal opportunities to producers, consumers, and traders. ICT can reflect changing consumption patterns and contain information that can be used by farmers when they decide what and how much to produce (FAO, 2018). Most studies recognized that facilitating market access through the provision of information on prices is the most frequent ICT application on agriculture (Okello, 2012; Okyere, and Mekonnen, 2012; Nakasone et al., 2014; Aker, 2010; Abebaw and Yared, 2018; Aprajita, 2018).

Many e-commerce and market applications are used in different countries. For instance, Reuter's RML Information Service in India, ECX, Improving Productivity and Market Success (IPMAS) in Ethiopia, Livestock Information Network Knowledge System (LINKS) in Tanzania, Kenya and Ethiopia are some of ICT based marketing service. A number of studies provide a range of estimates for the effect of price information on smallholders' sale prices and profits. Abebaw and yared (2018) found that farmers using ICTs were selling their produce at a higher price than farmers not using ICTs for most of the cereals. In Uganda farmers who access price information from ICT resulted in a 15 percent increase in farm-gate prices for maize. Similar effects are suggested by researchers in Peru and the Philippines (Beuermann, 2010; Labonne, 2010; Cole and Fernando, 2012).

\section{ICT for rural finance and insurance}

Money transfers, credit, savings, payments, and insurance are the basic financial services that are offered easily through ICTs. Since agriculture is the most risky business, insurance for farmers is a compulsory. ICTs can significantly help improve rural communities' access by providing financial institutions and insurance the means to enter rural markets through modern which can reduce need for high-cost branches and improved productivity of the staff in place (FAO, 2018). Mbirr and Mbanking in Ethiopia, M-PESA, DrumNet, Kilimo Salama in Kenya, CARE in East Africa, Digital finance in Nigeria, ACRE in Kenya, Rwanda, and Tanzaniav are some of ICT based service and application for finance and insurance(Greatrex, 2015; WB, 2016). 


\section{ICT for Rural health extension service}

Similarly, those most in need of basic and advanced health services (for example, people living in rural areas) often do not have access to them because health clinics are concentrated in urban areas and because of the lack of medical staff. Tele-medicine and other real-time diagnostic support can link health institutions and medical practitioners in different geographic locations, enabling them to share medical expertise and knowledge. E-health can also be used to train health professionals through online learning, to track diseases and to facilitate health promotion (WHO, 2016). In Malawi, Airtel 321 provides information on maternal and child nutrition, in the local language and via mobile phone. In Tanzania, The Registration Insolvency and Trusteeship Agency (RITA) and mobile operator Tigo, together with UNICEF and local governments, have developed an SMS-based application that makes the birth registration process more efficient, cost-effective and accessible for parents.

\section{ICT for indigenous and scientific knowledge management}

Knowledge management is a process that includes knowledge creation, identification, and utilization, storage, sharing and learning. Knowledge is developed through experimentation, adaptation, confrontation and other learning settings which result in knowledge products. In this regard, ICT can play a great role in all stage and process of knowledge management (UNDP, 2012; ATA, 2014).
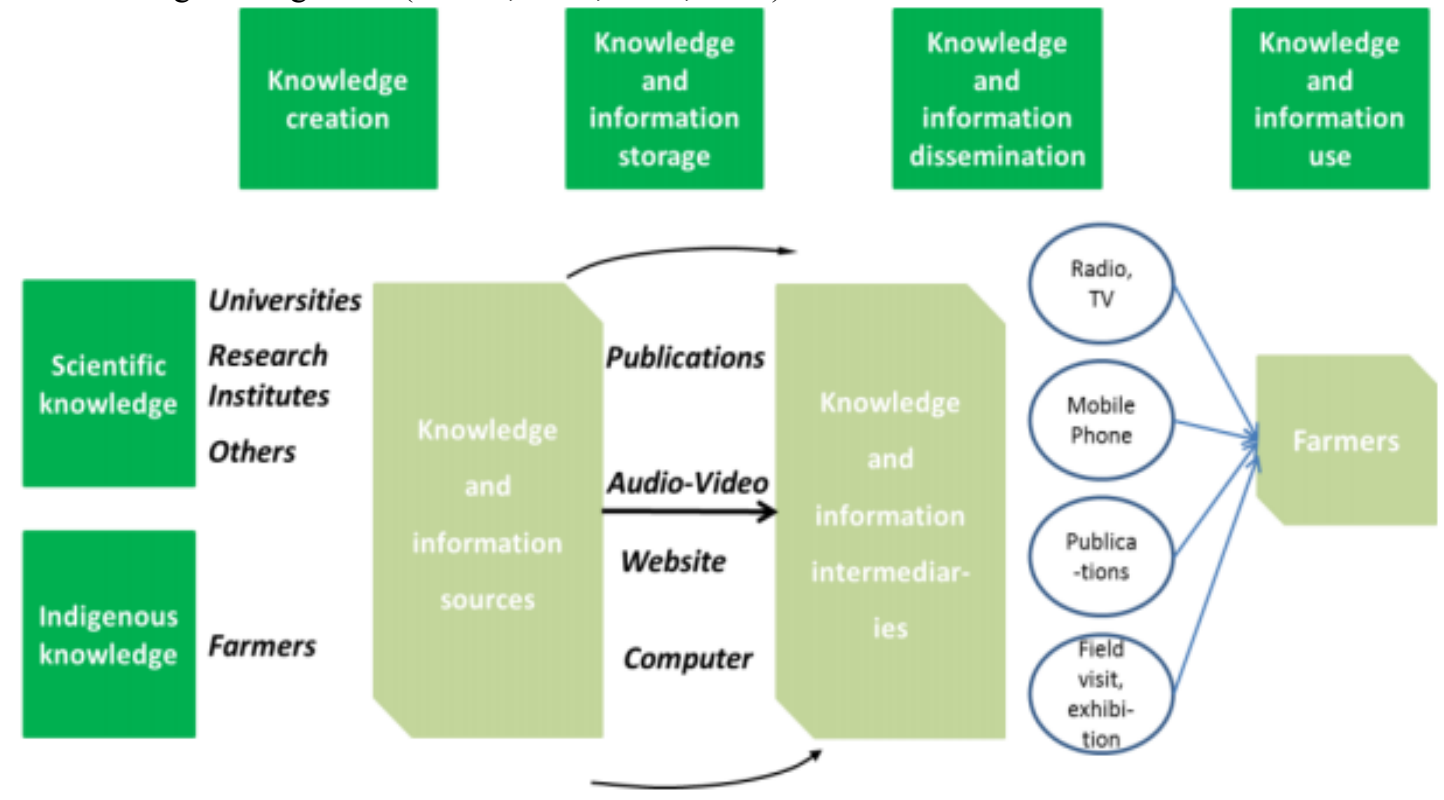

Figure 4: the role of ICT for knowledge management

\section{ICT for weather and early warning}

ICT-based tools related to climate change issues and early warning can assist in reducing the risks faced by smallholders. The provision of timely updates on local meteorological conditions can push out early warning messages related to extreme weather events such as possible flooding, heavy rainfall, unseasonal rain, pests, diseases, land slide and other natural hazards (FAO, 2018). For example, AfricaAdapt, in Senegal, Zambia National Farmer Union(ZNFU), : KenCall Farmers Helpline, Kilimo Salama, M-PESA, and Mali Shambani all in Kenya, Esoko, Coco alink and Radio Ada in Ghana, and MAKWACHA in Malawi that provide agricultural information, advice and support to smallholder farmers over the phone, using voice and voice callback to farmers (Payne et. al., 2010) facilitates vulnerable communities' access to information on climate change adaptation from researchers, policymakers and civil society organizations. It acts as a community of practice, and is supported by a website where members can share updates on face to face meetings about their work and adaptation techniques.

\section{Conclusion and possible suggestions}

It is already recognized that ICTs have been a significant contributor to growth, socio-economic development and for improving the livelihoods of rural people in developing countries. The radical penetration rate of ICTs in developing countries offers a great opportunity for dissemination of production, climate, health, insurance and market information for rural farmers. Nowadays, agriculture has transformed from labor intensive to knowledge intensive. ICT plays a great role in this regard for creation, dissemination, preservation and transformation of indigenous and scientific knowledge of rural people. In developing countries ICTs can have a profound impact on both efficiency (ICT as enabler for production and market efficiency through e-extension and e- agriculture), 
resilience (through dissemination of ICT based climate and early warning information) and inclusion (via ICT based financing and insurance). In different developing countries there are many ICT related applications and services designed for disseminating easily, timely and reliable agricultural related information for rural farmers.Based on the discussion, the following points are suggested;

- The possibility of ICT based extension service delivery can extend the reach of existing information and can be used to overcome the social and institutional barriers that currently limit remote and geographically displaced farmers' access to information.

- To improve the effectiveness of agricultural knowledge, it is essential to develop a mechanism that generates captures and disseminates knowledge and information through the use of effective processes and effective utilization of ICTs.

s There should be experience sharing between countries regarding to ICT based application and service installation and finally designing location-specific agricultural information.

근 Supply side infrastructures like electricity, telecommunication service, internet connection service and etc. have to be developed to enhance ICT coverage.

\section{References}

Abdulrahman, S., Abubakar, M. C., Suleiman H. A., Mohammed M., and Idris, J. 2017. Application of ICT in Agriculture: Opportunities and Challenges in Developing Countries. International Journal of Computer Science and Mathematical Theory, 3(1): 8-18.

Abebaw, A.,Yared, M. C. 2018: Factors Affecting the Use of Information and Communication Technologies for Cereal Marketing in Ethiopia, Journal of Agricultural \& Food Information, DOI: 10.1080/10496505.2018.1438290.

Aker JC. 2010. Information from Markets Near and Far: Mobile Phones and Agricultural Markets in Niger. Am. Econ.J.: Applied Economics. 2(3): 46-59.

Aprajita, S. 2018. Using Mass Media and ICT for Agriculture Extension: A Case Study. International Journal of Scientific \& Engineering Research, 9(2):73-81.

ATA (Agricultural Transformation Agency). 2014. National Strategy for Ethiopia's Agricultural Extension System. Vision, Systemic Bottlenecks and Priority Interventions, Addis Ababa, Ethiopia.

Bayissa, U.G.2014.A Study on Smallholder Farmers' Use of Information and Communication Technologies (ICT) to Get Access to Agricultural and Market Information, MSc thesis, Addis Ababa university, Ethiopia.

Beuermann D.W. 2011. Telecommunications Technologies, Agricultural Profitability, and Child Labor in Rural Peru.DT. N ${ }^{\circ}$ 2011-002 Working Paper, Central Reserve Bank of Peru.

Chukwunonso, F., Abubakar, M. and OBIDI, N. 2012.The Adoption Of Information And Communication Technology (ICT) In Agriculture In Adamawa STATE, NIGERIA, African Journal of Agricultural Research and Development, 5(3):79-85.

Cole, S.A and Fernando, A.N. 2012. The Value of Advice: Evidence from Mobile Phone -Based Agricultural Extension. Working Paper 13-047, Harvard Business School, Harvard University.

FAO (2013). Climate Smart Agriculture Sourcebook, Rome.

FAO. 2018. Information and Communication Technology (ICT) in Agriculture. A Report to the G20Agricultural Deputies; Food and Agriculture Organization of the United Nations Rome, Italy 2018.

Greatrex H, Hansen JW, Garvin S, Diro R, Blakeley S, Le Guen M, Rao KN, Osgood, DE. 2015. Scaling up index insurance for smallholder farmers: Recent evidence and insights. CCAFS Report No. 14. CGIAR Research Program on Climate Change, Agriculture and Food Security (CCAFS). Copenhagen.

Hopestone,K.C. 2014. the role of ICTs in agricultural production in Africa. Journal of development and agricultural economics, 6(7):279-389.

ITU. 2016. A review of Micro, Small and Medium Enterprises in the ICT Sector. http:// www.itu. int/ en/ mediacentre/ Pages/2016- PR48. Aspx

ITU. 2018. ICTs for LDCs and the SDGs Achieving universal and affordable Internet in the least developed countries, thematic report.

Labonne, J. and C. Robert S. 2010. The Power of Information: The Impact of Mobile Phones on Farmers' Welfare in the Philippines. World Bank Policy Research Working Paper Series, July.

Munyua, H. and Adera, E., 2009. Emerging ICTs and their potential in revitalzing small-scale agriculture. Agricultural information worldwide, 2(1), pp.3-9.

Nakasone, E., M. Torero, and B. Minten 2014. The Power of Information: The ICT Revolution in Agricultural Development. Annual Review of Resource Economics, Vol. 6: 533-550

Neelesh,P. 2017. Role of Information And Communication Technology In Agriculture Development: A Study Of Nabarangpur District. Scholedge International Journal of Business Policy \& Governance 4(4): 24-35. DOI: 10.19085/journal.sijbpg040401.

Okello, J.J, Kirui, K.O, Gitonga, M.Z., Njiraini, W.G and Nzuma, M.J. 2014. Determinants of awareness and use 
ICT-based market information services in developing-country agriculture: The Case of Smallholder Farmers in Kenya. Quarterly Journal of International Agriculture, 53 (3): 263-282.

Okyere, A. K. and Mekonnen, A.D. 2012. The Importance of ICTs in the provision of information for improving agricultural productivityand rural incomes in Africa. International Food Policy Research Institute (IFPRI), Working Paper WP 2012-015, UNDP. Regional Bureau for Africa, Addis Ababa. Retrieved from: http://web.undp.org/africa/knowledge/WP-2012-015-okyere-mekonnen-ict-

Pande, N. and Deshmukh, P., 2015. ICT: A Path towards Rural Empowerment through Telecommunication, Egovernance, and E-Agriculture. IBMRD's Journal of Management \& Research, 4(2): 47-54.

Payne, J., Woodard, J. and IRIS. 2010. ICT to Enhance Farm Extension Services in Africa. Briefing Paper. USAID.

Tigistu, K. 2014. Determinant of Mobile Phone Use for Dissemination of Maize Technology in Lanfuro District, Southern Region, Ethiopia, MSc thesis, Haramaya university, Ethiopia.

UNDP. 2012. Promoting ICT based agricultural knowledge management to increase production and productivity of smallholder farmers in Ethiopia

World Bank Group 2016. Digital Dividends. World Development Report 2016.

World Bank Group. 2016. Digital Dividends. World Development Report 2016

Yonazi, E., T. Kelly, N. 2012. Halewood and C. Blackman (2012). "eTransform Africa:The Transformational Use of ICTs in Africa. Chapter 3: ICT for climate change adaptation in Africa. World Bank report (2012). 